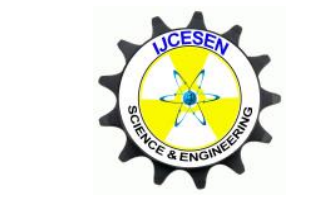

Copyright (C) IJCESEN
International Journal of Computational and

Experimental Scienceand Engineering

(IJCESEN)

Vol. 4-No.2 (2018)pp. 1-7

http://dergipark.gov.tr/ijcesen

ResearchArticle

\title{
Influence of Spinning Parameters on thin and thick Places of rotor spun yarns
}

\author{
Josphat Igadwa MWASIAGI ${ }^{1 *}$, Jacquirine MIREMBE ${ }^{2}$
}

${ }^{1}$ School of Engineering, Moi University, Po Box 3900-30100, Eldoret, Kenya

${ }^{2}$ Fine Spinners, Po Box 3794, Kampala, Uganda

* Corresponding Author : igadwa@gmail.com ORCID: 0000-0002-9983-2573

(First received 16 March 2017 and in final form 11 April 2018)

\section{Keywords}

Cotton yarns

Thin places

Thick places

Spinning parameters

\begin{abstract}
Production of better yarns in terms of uniformity is every spinner's goal since yarns with a large number of irregularities and defects reduces the market value of the end product. This study aimed at studying the influence of count, twist, opening roller speed and rotor speed on the number of thin and thick places formed in $100 \%$ cotton rotor spun yarns using statistical techniques. The results obtained in this research work indicated that increase in count increased thin and thick places in the yarns. With twist and opening roller speed, thin and thick places were reduced up to a certain value and then started to increase. Count $15 \mathrm{Ne}$, twist multiplier of 5TM, opening roller speed of $8000 \mathrm{rpm}$ and rotor speed of 90,000rpm gave the lowest number of thin and thick places $/ \mathrm{km}$ formed in the resulting yarns.
\end{abstract}

\section{Introduction}

Yarn imperfections result from the variation in the number of fiber ends per unit length and are in the form of thick places, thin places and neps. Thick and thin places not only affect the quality of yarns but also adversely affect the subsequent process, and the final application of the end product. Yarns with higher number of thick and thick places, causes more breakages in spinning, lower efficiency in winding, warping and weaving. Thick and thin places will also affect the final coloartation process and the final fabric may not have the desiered appearance. Thick places are yarn defects characterized by a diameter greater than that of the adjoining segments and extending $6 \mathrm{~mm}(1 / 4 \mathrm{in})$ in length. These mostly result from poor drafting of fibers during yarn formation. Thin places on the other hand are yarn defects characterized by a segment that is substantially smaller (at least $25 \%$ smaller in diameter) than the average diameter of yarn and are normally caused by variation in sliver and yarn count [1]. Research has shown that ineffective opening and cleaning of the in-feed material, poor piecing of yarn breaks during spinning, twisting in of loose airborne fibers and defective operation of machinery all contribute to the higher level of thin and thick places formed in yarns. Kong, Platfoot and Wang [2] reported that increase in rotor speeds increased the coefficient of mass variation $(\mathrm{CV} \%)$ and imperfections but the level decreased as the opening roller speed increased from 5000-7000 beyond which they (thin and thick places) started to increase. Similar results were obtained by other researchers [3-4]. Increase in yarn count, yarn twist and type of rotor used during spinning all lead to increase in the formation of thin and thick places [5]. Thin and thick places bring about a poor yarn and fabric appearance, lower yarn strength hence increasing in end breakages in yarns during winding, weaving and knitting operations. With these side effects, spinners should ensure that thin and thick places are minimized so as to produce yarns of the desired quality. This study thus focused on the influence of the selected factors (count, twist, roller speed and 
rotor speed) on the formation of thin places and thick places in cotton rotor spun yarns.

\section{Materials and Methods}

The yarns used in this research work were spun in a textile factory in Uganda which prefered to remain anonymous. For a given bales of cotton lint, cotton lint samples were collected and tested using High Volume Instrument as per ASTM D5867-2005 standard and the results are given in Table I. The cotton bales were processed from blow room to finisher drawframes at constant machine settings.

Table 1. HVI cotton fibre properties

\begin{tabular}{|l|c|}
\hline Fibre Property & Mean \\
\hline Micronaire & 4.3 \\
\hline Length (mm) & 28.54 \\
\hline Uniformity Index (\%) & 83 \\
\hline Short Fibre Content (\%) & 6.7 \\
\hline Strength (g/tex) & 28.6 \\
\hline Elongation (\%) & 7 \\
\hline Trash Content & 26 \\
\hline
\end{tabular}

Using the Taguchi Experimental Design, yarns were spun from the samples at varying values of count $(15 \mathrm{Ne}$ and $24 \mathrm{Ne})$, twist multiplier $(4.4,5.0$ and 5.5TM), opening roller speed $(7000,8000$ and 9000rpm) and rotor speed $(80000,90000$ and $100,000 \mathrm{rpm})$. A total of 180 yarn cones were spun and tested for properties of strength, elongation, evenness and imperfections. This paper however concentrated on thin and thick places/ $/ \mathrm{km}$ tested using a Uster tester machine according to ASTMD 1425- 1996 standard.

Using Minitab 17.01 statistical software tool, Analysis of variance (ANOVA) was employed to analyze the data used in this research work. Main effect plots and interaction plots were used to investigate the effect of selected variables on thin and thick places $/ \mathrm{km}$ formed in cotton rotor spun yarns. The first study considered one variable at a time (while the other three were kept constant) and it was referred to as the effect of single variable on either thin or thick places $/ \mathrm{km}$ while the second study investigated the effect of two variables (while keeping the other two constant) and it was referred to as the combined effect of two variables on a given yarn characteristic (thin or thin places).

\section{Results and Discussions}

\subsection{Effect of Single Variables on Thin Places/km}

The effect of each single variable on thin places $/ \mathrm{km}$ was investigated by keeping three factors constant and studying how one factor affects thin and thick places and the results are given in Figure 1.

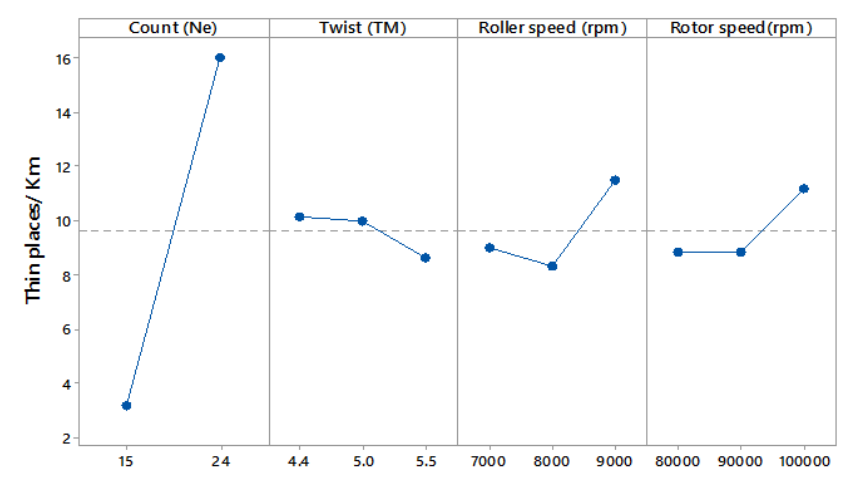

Figure 1. Effect of a single selected variable on thin places

By keeping twist, opening roller speed and rotor speed constant, the effect of count on the number of thin places $/ \mathrm{km}$ showed that an increase in count from $15 \mathrm{Ne}$ to $24 \mathrm{Ne}$ increased the number of thin places in the spun yarns. This may have been attributed to reduced number of fibers in the yarn cross section as regards to finer counts causing spinning difficulties and hence contributing to thin places in the yarns [6]. When twist was studied, it was found out that between 4.4 and 5TM, the level of thin places in the yarns was almost constant but it reduced in the 5-5.5TM range. This is probably because increase in twist compacted the yarn very tightly together which ultimately reduced the number of weak places in the yarn. Studying opening roller speed at a constant twist, count and rotor speed indicated that the level of thin places $/ \mathrm{km}$ decreased as the opening roller speed increased but beyond 8000rpm, the number of thin places increased sharply. High opening roller speeds facilitated better fibre opening and separation which improved the fibers' alignment in the transportation and rotor groove hence ultimately reducing thin places. Further increase in opening roller speed on the other hand caused fiber rupture which contributed to the number of thin places in yarns [2,3,7]. Kumar and Ishtiaque [8] reported that increasing opening roller speed at a constant rotor 
speed increases the speed of air stream associated with the opening roller which leads to a strong turbulence in the stripping zone due to an interaction between sucked air and the associated air stream which affects the yarn's uniformity. With rotor speed, the level of thin places $/ \mathrm{km}$ was constant with an increase in rotor speed from $80,000 \mathrm{rpm}$ to $90,000 \mathrm{rpm}$ beyond which it increased. At high rotor speeds, the number of wrapper fibers is reported to increase which disturbs the fiber arrangement in the rotor groove leading to unevenness and imperfections [4,5,9]. Tao, Lo and Lau [10] reported that higher rotor speeds increase the twisting torque at yarn formation point which results into poor fibre orientation and hence increasing the number of imperfections.

\subsection{Combined Effect of Two Variables on Thin Places/km}

The combined effect of variables on the occurrence of thin places $/ \mathrm{km}$ in yarns was investigated using Figure 2. This was achieved by studying two factors at the same time while keeping the other two factors constant. Values on the Y- axis represent the number of thin places formed in the yarn while the $\mathrm{X}$-axis represents the factors being investigated.

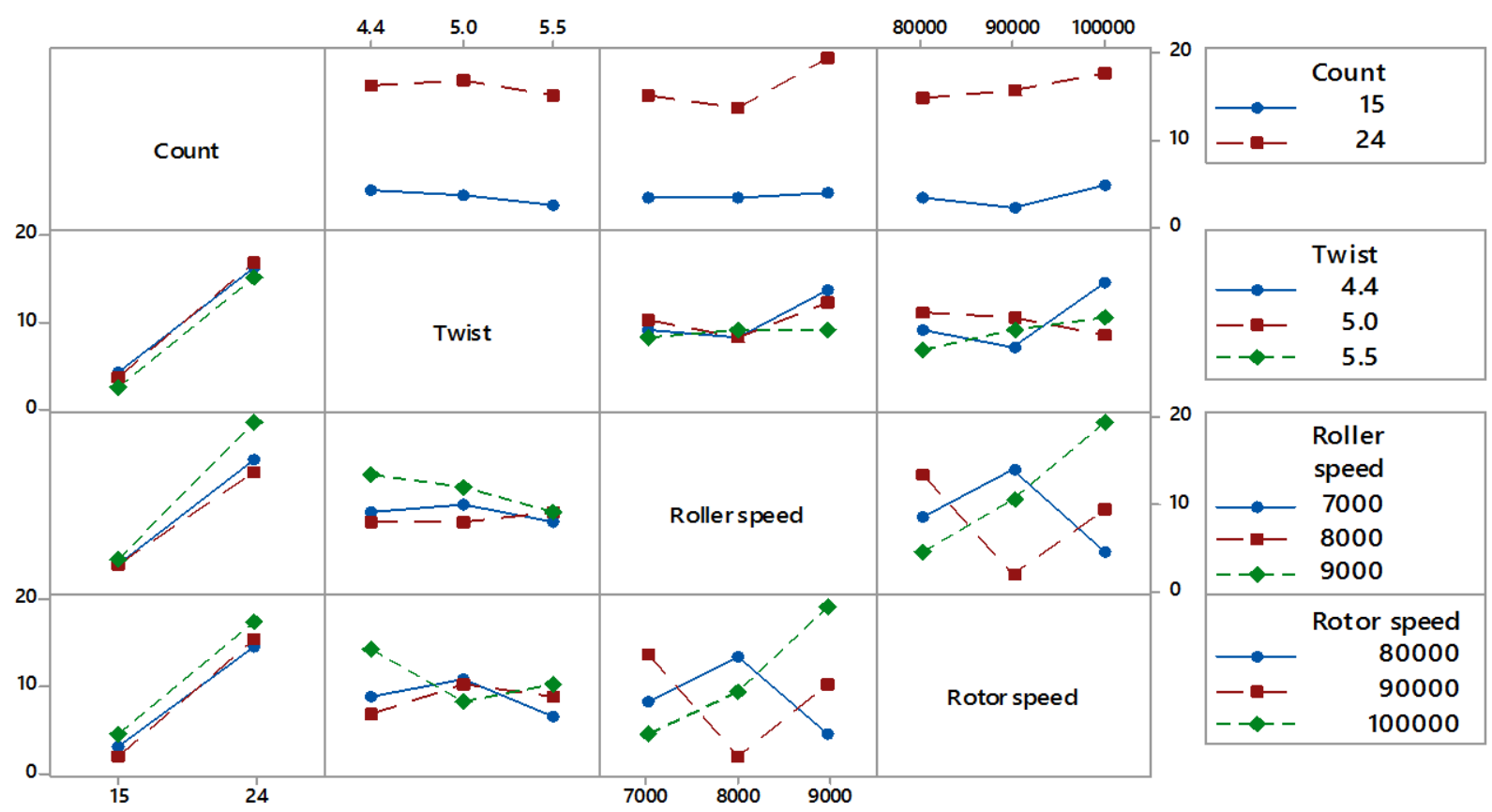

Figure 2. Combined effect of variables on thin places

It was observed from Figure 2 that when the effect of count and twist was studied, results indicated that at a coarse count $(15 \mathrm{Ne})$, increase in twist led to a tremendous reduction in thin places $/ \mathrm{km}$ while at a finer count $24 \mathrm{Ne}$, thin places increased with an increase in twist from 4.4-5TM but later decreased in the 5-5.5TM range. For count and opening roller speed, at count $15 \mathrm{Ne}$, any increase in opening roller speed had no significant influence on the level of thin places $/ \mathrm{km}$. For count $24 \mathrm{Ne}$, an increase in roller speed from 7000rpm to 8000rpm led to a decrease on the level of yarn thin places but a further increase in speed increased the number of thin places $/ \mathrm{km}$. This could be attributed to the reasons explained earlier that high opening roller speeds facilitated fiber opening and individualization but as the speeds increased the fibers could be overstretched leading to fiber breakages. Studying count and rotor speed revealed that, at count $15 \mathrm{Ne}$, an increase in rotor speed reduced the number of thin places $/ \mathrm{km}$ up to 90000rpm beyond which thin places increased. At a finer count $24 \mathrm{Ne}$, any given increase in rotor speed led to an increase in the number of thin places $/ \mathrm{km}$.

When twist was studied in relation to other factors, the following was observed. For twist and count, the number of thin places was low for count $15 \mathrm{Ne}$ with any increase in twist but at count $24 \mathrm{Ne}$, any increase in twist led to a drastic increase in thin 
places. All twist levels showed an increase of thin places when count was changed from $\mathrm{Ne} 15$ to $\mathrm{Ne}$ 24.

Studying the combined effect of twist and opening roller speed showed that, at 4.4TM and 5TM, the yarn's level of thin places was constant with increase in roller speed from 7000-8000rpm beyond which it increased while at 5.5TM, the level was constant with any given increase in opening roller speed. At high twist levels, production rate is low hence fibers spend a lot of time in the opening region and become thoroughly opened which reduces on yarn imperfections but at excessive roller speed and twist, they will instead break. Considering twist and rotor speed showed that at 4.4TM, thin places $/ \mathrm{km}$ reduced with increase in rotor speed from 80,000-90,000rpm beyond which it increased. At 5TM, thin places gradually reduced with increase in rotor speed while at 5.5TM, the number of thin places was observed to increase with any increase in rotor speed from 80,000$100,000 \mathrm{rpm}$. Higher twist levels coupled with high rotor speeds negatively affects the yarn's uniformity by increasing the end breakage rate hence contributing to thin places.

By studying the combined effect of opening roller speed and count, results showed that fewer thin places were obtained at count $15 \mathrm{Ne}$ irrespective of changes in opening roller speed. This was confirmed by overlapping interactions where all roller speeds gave a similar number of thin places $/ \mathrm{km}$. For count $24 \mathrm{Ne}$, as expected, thin places increased with increase in opening roller speed. The combined effect of roller speed and twist indicated that at 7000rpm, thin places increased with increase in twist in the 4.4-5TM range and then decreased in the 5-5.5TM range. When 8000rpm was used, thin places were constant with increasing twist but beyond 5TM, they increased. However, at 9000rpm, thin places decreased steadily with any increase in twist. This could be an indication of serious spinning defects, which could include fiber breakage. Combining opening roller and rotor speed showed that, at 7000rpm, thin places increased drastically with increase in rotor speed up to $90,000 \mathrm{rpm}$ and then reduced. Spinning at 8000rpm showed that as the rotor speed increased, thin places also reduced but beyond 90,000rpm, they instead increased. Increasing the roller speed to 9000rpm as expected gave a sharp increase in the number of thin places for any given increase in rotor speed. This may have been contributed to increased breakages associated with high roller and rotor speeds $[3,8,9]$.

The combined effect of rotor speed and count indicated that at any level of rotor speed, thin places were low for count $15 \mathrm{Ne}$ and the reverse was true for the finer count $(24 \mathrm{Ne})$. Combined effect of twist and rotor speed revealed that at 80,000 and $90,000 \mathrm{rpm}$, thin places increased with increase in twist up to 5TM beyond which there was a sharp decrease in 5-5.5TM range for 80,000rpm compared to $90,000 \mathrm{rpm}$. Interestingly, spinning at $100,000 \mathrm{rpm}$ reduced on the number of thin places with increasing twist in the first range and then increased in the second one. For rotor and opening roller speed, at $80,000 \mathrm{rpm}$ thin places increased with increase in opening roller speed but beyond 8000rpm, they reduced. At low opening-roller speeds, the degree of fiber separation will be lower and the yarn may become more irregular, with increases in the number of thin places. A study done by Khalilur and Habibur [10] reported that a roller speed of 8500rpm gave better yarn properties. Spinning at 90,000rpm gave the best results as the level of thin places decreased tremendously with increasing roller speeds up to 8000rpm and then increased. As expected higher rotor speed of $100,000 \mathrm{rpm}$ increased the level of thin places $/ \mathrm{km}$ at any given increase in roller speed. This could be due to reasons discussed earlier on.

According to the results obtained in this research work lower thin places could be obtained by spinning cotton yarn of count $15 \mathrm{Ne}$, at a twist multiplier of 5TM, opening roller speed of $8000 \mathrm{rpm}$ and rotor speed of 90,000rpm.

\subsection{Effect of Single Variables on Thick Places/km}

The effect of each single variable on thick places $/ \mathrm{km}$ was investigated and the results are given in Figure 3, which showed that at constant twist, roller speed and rotor speed, the number of thick places increased drastically with increase in count. For coarse counts, the yarn diameter and number of fibers in the yarn cross section increases enabling the yarns to be able to withstand higher 
spinning tensions. Since more fibers per crosssection lead to better spinnability, the number of thin places are likely to reduce. An investigation of the effect of twist showed that thick places reduced with an increase in twist up to 5TM beyond which it increased. Studying the effect of opening roller speed indicated that, thick places reduced with an increase in speed but beyond 8000rpm, the number

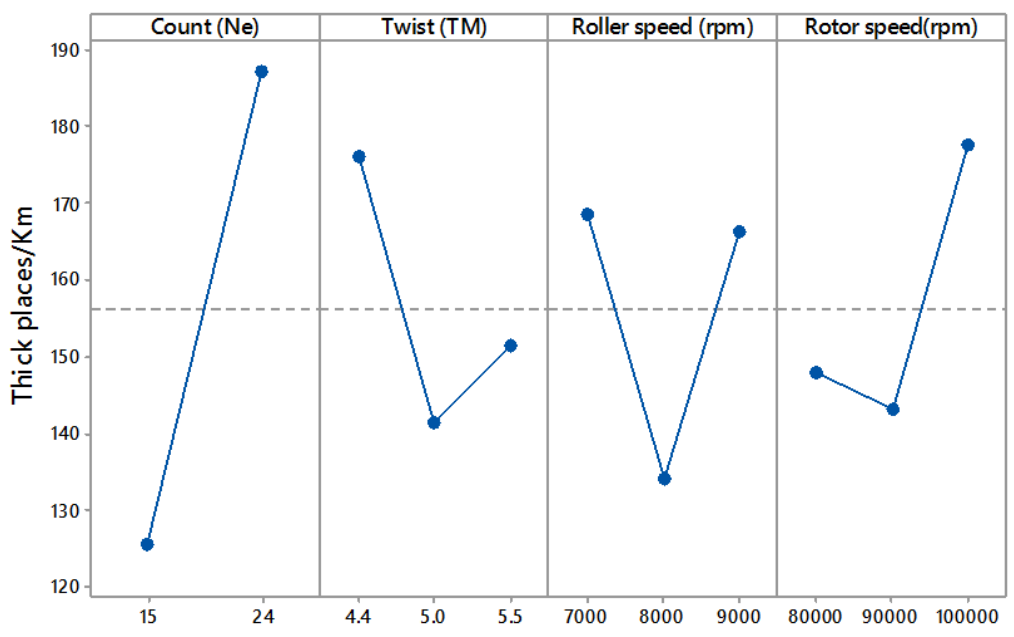

Figure 3. Influence of single variables on thick places $/ \mathrm{km}$ of thick places increased in the 8000-9000rpm range possibly due to increased breakages associated with higher rotor speeds. When rotor speed was considered, thick places were observed to decrease with increase in rotor speed up to 90,000rpm after which it increased.

\subsection{Combined Effect of Variables on Thick Places $/ \mathbf{k m}$}

The combined effect of the selected variables on the formation of thick places was studied and the results are given in Figure 4.

The combined effect of count and twist when opening roller speed and rotor speed were kept constant indicated that at count $15 \mathrm{Ne}$, thick places reduced with increase in twist from 4.4 to 5TM after which it increased. With count $24 \mathrm{Ne}$, thick places reduced with increase in twist. This could be due to the fact that finer yarn needs more twist than a coarse yarn in order to have the same twist characteristics. For count and opening roller speed, increasing roller speed from 7000rpm-8000rpm led to a decrease in thick places $/ \mathrm{km}$ for both counts but further increase in speed to 9000rpm led to a sharp increase in thick places for a finer count and a leveling out for a coarse count. Combining count and rotor speed revealed that, at a coarse count, increase in rotor speed reduced on the number of thick places formed per km but beyond 90,000rpm, the level of thick places inreased. For a finer count thick places increased for any increase in rotor speed. Higher rotor speeds increases the formation of wrapper fibers in the yarn which disturb the fiber arrangement in the rotor groove. Thic could have lead to increased yarn unevenness and imperfections $[6,8,9]$.

A combination of twist and count indicated that thick places $/ \mathrm{km}$ were lower for count $15 \mathrm{Ne}$ for any increase in twist the effect being more signifinant at a twist multiplier of 5TM but reverse results were obtaind for count $24 \mathrm{Ne}$. For twist with opening roller speed, it was observed that at any given level of twist, thick places $/ \mathrm{km}$ reduced with increasing roller speeds from 7000rm but beyond 8000rpm, the level of thick places increased. This effect was also very significant at a twist multiplier of 5TM. Increase in twist binds the yarn more tightly together which reduces on the number of thick places $/ \mathrm{km}$. Considering twist and rotor speeds showed that at $4.4 \mathrm{TM}$, the thick places decreased with increase in rotor speed up to $90,000 \mathrm{rpm}$ and then thick places increased drastically. At 5TM, thick places were seen to reduce gradually with any level of rotor speed but at 5.5TM, opposite results were observed. This may be due to the fact that higher twist levels may have resulted in improper twist propagation during yarn formation. Coupled with higher rotor speeds this may have lead to an increase in the formation of thick places $/ \mathrm{km}$ in the yarn. 


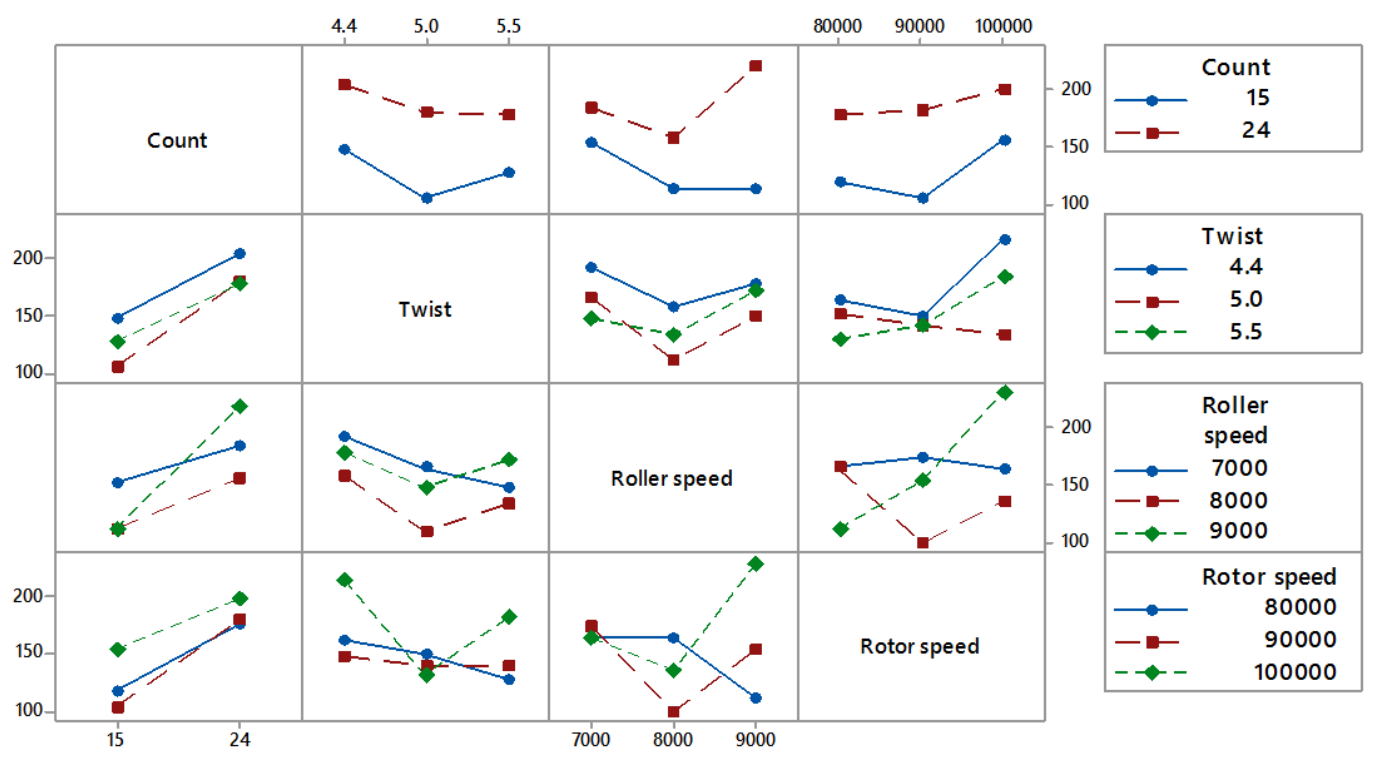

Figure 4. Combined effect of selected variables on thick places $/ \mathrm{km}$

The combined effect of opening roller speed in relation to other factors showed that the level of thick places were lower for count $15 \mathrm{Ne}$ at any given level of opening roller speed and this was very significant at 8000 and 9000rpm where a similar number of thick places was observed. For count $24 \mathrm{Ne}$ as expected, any increase in opening roller speed caused a significant increase in thick places/km especially at $9000 \mathrm{rpm}$. When twist was considered, the level of thick places reduced steadily with any increase in twist at 7000rpm. This justifies the statement made earlier that at high twist levels, fibers spend a lot of time at the opening roller region hence become thoroughly opened and inso doing evening out the yarn which reduces on the number of thick places formed in the yarn. At 8000 and 9000rpm, thick places reduced with an increase in twist but beyond 5TM, the level increased as it has earlier been discussed. Combining opening roller and rotor speed showed that, at 7000rpm, thick places increased with increase in rotor speed up to $90,000 \mathrm{rpm}$ beyond which it showed a slight reduction. When yarns were spun at $8000 \mathrm{rpm}$, thick places decreased sharply with increase in rotor speed up to 90,000rpm and then increased. High speeds faciliatate better fibre opening and orientation which reduces on poor fibre drafting and hence a reduction in thick places $/ \mathrm{km}$. At $9000 \mathrm{rpm}$ as expected, the thick places increased tremendously with any given increase in rotor speed.
The combined influence of rotor speed verses other factors was also studied and the following results were obtained. Increasing rotor speed at any given level negatively affected the number of thick places with increasing count. For count $15 \mathrm{Ne}$, 90,000rpm gave the lowest number of thick places $/ \mathrm{km}$. When rotor speed was studied in relation to twist, it was observed that at 80,000 rpm, thick places decreased with any given increase in twist. At 90,000rpm, the number of thick places was almost constant with any given increse in twist while at 100,000rpm, thick places decreased with increase in twist upto 5TM beyond which it increased. For opening roller and rotor speed, thick places were constant at $80,000 \mathrm{rpm}$ with increase in roller speed from 7000 to $8000 \mathrm{rpm}$ beyond which it decreased. At 90,000 and 100,000rpm, thick places decreased with increase in roller speed but after 8000rpm the number of thick places increased. This effect was very significant at $90,000 \mathrm{rpm}$. Higher rotor speeds may have lead to improper straightening of the fibers in the rotor groove due to short contact time before yarn formation which may have contributed to the incidences of more thin places $/ \mathrm{km}$ [9].

From the data obtained in this research work the optimum variable setting for low value of thick places was spinning count of $15 \mathrm{Ne}$, twist multiplier of 5TM, opening roller speed of 8000rpm and rotor speed of 90,000rpm.

\section{Conclusion}


In this study, the influence of count, twist, opening roller speed and rotor speed on the number of thin and thick places in $100 \%$ cotton rotor spun yarn was investigated. Increase in count increased both defects (thick and thin) in the yarns. With twist and opening roller speed, both defects were reduced up to a certain value and then started to increase. Thin places were constant with increase in rotor speed up to a certain value beyond which they increased while for thick places, there was a reduction and later on an increase. Combined effect of any two factors taken at a time showed an increase in the number of thick and thin places. Considering the levels for the four variables investigated, it can be concluded that a better cotton roto spun yarn in terms of reduced thin and thick places can be obtained by spinning count $15 \mathrm{Ne}$, at a twist multiplier of 5TM, opening roller speed of $8000 \mathrm{rpm}$ and rotor speed of 90,000rpm.

\section{Acknowlegement}

The authors are grateful for the funding provided by the METEGA project. We are also grateful for the samples and data provided by the textile factories and institutions in Uganda.

\section{References}

[1] C.A. Lawrence, Fundamentals of Spun Yarn Technology; Boca Raton London New York Washington: CRC Press LLC, 2003.

[2] Kong, L. X., R. Platfoot, X. Wang “ Effects of Fiber Opening on the Uniformity of Rotor Spun Yarns” Textile Research Journal. 66-1 (1996)3036, DOI: 10.1177/004051759606600105

[3] Khan, M.K.R., M. M. Hossain, R. C. Sarker "Statistical Analyses and Predicting t he Properties of Cotton/Waste Blended Open-End Rotor Yarn Using Taguchi OA Design". International Journal of Textile Science.4-2(2015)27-35. DOI:10.5923/j.textile.20150402.01

[4] F. Ahmed, F. S. Saleemi, A. W. Rajput, I. A. Shaikh ,A. R. Sahito "Characterization of Rotor Spun Knitting Yarn at High Rotor Speeds"Technical Journal, University of Engineering and Technology Taxila, Pakistan. 19-4 (2014)73-78.

http://web.uettaxila.edu.pk/techjournal/2014/Techni cal_Journal_Vol19_No4_2014.pdf

[5] Taher, H.M., B. Azzouz, B. H. Mohamed, S. Faouzi "Influence of Spinning Parameters and Recovered Fibers from Cotton Waste on the Uniformity and Hairiness of Rotor Spun Yarn" Journal of Engineered Fibers and Fabrics. 2009, 43(2009) 36-44.
https://www.jeffjournal.org/papers/Volume4/4.3Ta her36-44.pdf

[6] Das, A., S.M. Ishtiaque “ End Breakage in Rotor Spinning: Effect of Different Variables on Cotton Yarn End Breakage" Autex Research Journal. 2 (2004)

52-59. http://autexrj.com/cms/zalaczone_pliki/1-04-2.pdf

[7] Wanassi B., B. Azzouz, M.B. Hassen "Recycling of Post-Industrial Cotton Wastes: Quality and Rotor Spinning of Reclaimed Fibers" International Journal of Advanced Research. 3-6 (2015) 94-103. http://www.journalijar.com/uploads/144_IJAR5785.pdf

[8] Ishtiaque, S M, P. Kumar " Ishtiaque "Impact of rotor and opening roller speeds on configuration of fibres in yarns" Indian Journal of Fibre and Textile Research., $\quad 19 \quad$-2(1994)71-75. DOI:http://nopr.nidcair.res.in/handle/123456789/32 415

[9] Khan, M. K., H. Rahman "Study of Effect of Rotor Speed, Combing-Roll Speed and Type of Recycled Waste on Rotor Yarn Quality Using Response Surface Methodology"Journal of Polymer and Textile Engineering. 2 (2015) 47-55. http://www.iosrjournals.org/iosr-jpte/papers/Vol2issue1/H0214755.pdf

[10] Tao, X. M., W.K. Lo, Y.M. Lau “Torque Balanced Singles Knitting Yarns By Unconventional Systems. Part I: Cotton Rotor Spun Yarn'Textile Research Journal.67 -10(1997) 739746. DOI: $10.1177 / 004051759706701006$ 